\title{
DE RÉU A REI - O CASO DO BIÓGRAFO DE ROBERTO CARLOS
}

\section{Patrícia Asari}

Universidade do Oeste Paulista - UNOESTE, Especialização em Literatura e Jornalismo, Presidente Prudente, Estado de São Paulo. e-mail: patiassari@hotmail.com

\section{RESUMO}

A publicação das obras de Paulo César de Araújo sobre o cantor e compositor Roberto Carlos fomentou o debate sobre os limites entre liberdade de expressão e direito à privacidade. 0 objetivo deste artigo foi analisar a discussão gerada e como a biografia, gênero do jornalismo literário tem a complexa tarefa de estar comprometida com a verdade, princípio do jornalismo, e com a liberdade e fluidez que são inerentes a todas as artes. Concluímos que o hibridismo da biografia torna a divisão entre liberdade de expressão e privacidade uma linha muito tênue e que, por isso, uma decisão do Supremo Tribunal Federal se fez necessária para garantir a publicação de biografias independentemente da autorização dos biografados no Brasil.

Palavras-chave: Roberto Carlos, Paulo César de Araújo, liberdade de expressão, biografia, jornalismo literário

\section{FROM DEFENDANT TO KING - THE CASE OF THE BIOGRAPHER OF ROBERTO CARLOS}

\begin{abstract}
The release of Paulo César de Araújo's books on singer and composer Roberto Carlos promoted the debate on the limit between freedom of speech and the right to privacy. The objective of this article was to analyze the discussion generated and how biography, genre of literary journalism has the delicate task to be committed to the truth, a journalistic principle and with the freedom and fluidity, which are inherent to all forms of art. We concluded that the hybridism of biography makes the line between freedom of speech and privacy very thin and that a decision of the Federal Supreme Court was necessary to guarantee the publishing of non-authorized biographies in Brazil. Keywords: Roberto Carlos, Paulo César de Araújo, freedom of speech, biography, literary journalism
\end{abstract}




\section{INTRODUÇÃO}

O curioso caso do fã que se tornou réu por publicar a biografia de seu ídolo deu origem a um imbróglio judicial que durou anos e incitou o debate sobre o direito de escrever e publicar biografias sem o consentimento do biografado.

O objetivo deste estudo foi apresentar o caso emblemático na questão de liberdade de expressão de escritores na recente história do país e demonstrar a sagacidade do escritor que, mesmo impedido de vender sua obra, conseguiu contar sua história e a de seu objeto de estudo, e como sua trajetória de fã a estudioso, de biógrafo a réu e, posteriormente, a defensor do direito dos escritores ajudou a garantir que se contem histórias que são muito maiores do que algumas pessoas.

\section{METODOLOGIA}

Este artigo é uma pesquisa qualitativa bibliográfica do tipo descritiva explicativa, na qual será desenvolvida a análise dos conflitos do direito à liberdade de expressão com o direito à intimidade e à vida privada, concentrando os estudos no caso da publicação e proibição de uma biografia de Roberto Carlos.

O presente estudo baseia-se na análise de literatura presente em livros, artigos, periódicos, análise de caso judicial e legislação.

\section{DISCUSSÃO}

Quando estamos diante de uma biografia, presumimos que seu conteúdo retrate a vida de uma pessoa, o que a afetou e o que foi por ela afetado. Quando a capa traz a expressão "não autorizada" somos levados a imaginar que talvez traga fatos que o biografado gostaria de omitir, mas também temos de considerar que é possível que o biógrafo tenha tido menor acesso a informações que apenas o biografado ou pessoas muito próximas conhecessem. Por outro lado, se estamos diante de uma biografia autorizada, é esperado que apenas fatos que enalteçam o biografado sejam contados, ou que a narrativa favoreça a imagem do biografado.

Segundo Jacques Le Goff (1989): "a biografia histórica deve se fazer, ao menos em um certo grau, relato, narração de uma vida, ela se articula em tomo de certos acontecimentos individuais e coletivos - uma biografia não événementielle não tem sentido (...)". A biografia transita pelo campo da história, do jornalismo e da literatura. Há o levantamento de dados, a verificação da autenticidade do que se averigua e o tratamento da linguagem para a produção da narrativa da vida de alguém que sempre ultrapassa o indivíduo. Ao contar a história de uma vida, muitas outras são envolvidas, muitos fatos estão entrelaçados para a contextualização da narrativa. A biografia de um indivíduo é formada pelas biografias de muitos outros e, diferentemente do que pensou Roberto Carlos, não é propriedade daquele cuja vida desperta o interesse de pesquisadores, escritores e leitores.

Paulo César Araújo, entusiasta fã de Roberto Carlos desde a infância, dedicou anos de sua vida pesquisando a vida de seu ídolo. Em 2006, lançou Roberto Carlos em detalhes, grande biografia do ícone da música brasileira. Logo após o lançamento, atingiu altos níveis de vendagem e a crítica cobria a obra de louros. O minucioso trabalho foi fruto de centenas de entrevistas com grandes personalidades da MPB e pessoas importantes na vida do cantor. Os fatos foram coletados por um estudioso, jornalista e historiador, e deram forma a uma narrativa cuidadosa, abrangente e envolvente da vida do cantor e da música brasileira em décadas que foram palco de muitas mudanças históricas e políticas no país.

Entretanto, oito dias após o lançamento, Roberto Carlos acionou a justiça com dois processos, um contra a Editora Planeta e outro contra o Autor, acusando-o de invadir sua privacidade. 
Em 27 de Abril de 2007, depois de audiência de conciliação na Vigésima Vara do Fórum Criminal de São Paulo, o cantor e compositor Roberto Carlos saiu vitorioso nos dois processos. A decisão proibiu a edição e a venda do Livro em todo o Brasil. Os livros foram apreendidos e Roberto Carlos tinha a intenção de incinerá-los, como já havia ocorrido com o livro O Rei e Eu, livro do ex-mordomo Nichollas Mariano, publicado em 1979, mas, devido à grande comoção surgida com o caso, foi aconselhado a não queimá-los. Os onze mil exemplares ficaram então em um depósito.

Ainda em 2007, o autor contestou a decisão que vetara sua obra e a batalha judicial entre Paulo Cesar de Araújo e Roberto Carlos passou a envolver outras personalidades. Ironicamente, artistas que sofreram com a censura imposta nos anos da ditadura militar a partir do final da década de 60, representados no grupo Procure Saber, que incluía Caetano, Gilberto Gil e Chico Buarque, posicionaram-se contra a publicação de biografias não-autorizadas. A atitude do cantor, e de seus colegas que a endossaram, produziu efeitos nocivos à imagem dos ídolos. Roberto disse mais de uma vez que "não leu e não gostou" da biografia. Talvez se tivesse lido, veria que o objeto de sua ira tratava-se de uma homenagem de uma pessoa que reunia a dedicação emocional de um fã e o cuidado profissional e acadêmico de um jornalista e historiador.

O caso é um exemplo gritante de agressão à liberdade de expressão e ocupou os principais veículos de comunicação e foi discutida por pessoas de diversas esferas: juristas, personalidades da política, da cultura e das artes, pessoas comuns.

O escritor Paulo Coelho, alvo de muitas críticas por suas obras e sua vida mística, defendeu na imprensa os direitos dos biógrafos. Interessantemente, sua biografia, escrita por Fernando Morais também originou reclamações, mas, diferentemente de Roberto Carlos, não do próprio biografado, mas de Celso Lafer, ex-ministro, acusado de pedir votos para Hélio Jaguaribe para a Academia Brasileira de Letras em troca de favores. Lafer negou o episódio narrado na biografia de Paulo Coelho e processou a editora.

Paulo César de Araújo declarou em entrevista ao portal uol: "Eu fiz o livro para ser lido". Neste ponto, ele sempre foi vitorioso, mesmo quando ainda acumulava somente derrotas nos tribunais.

A repercussão do caso aumentou o interesse pela obra proibida "Roberto Carlos em detalhes", vendida em sebos (trinta mil exemplares haviam sido vendidos antes da proibição), em versões piratas e na internet, onde o livro "proibido" é facilmente encontrado para download.

No estande da editora Leya na 86a Feira do Livro de Lisboa, era possível adquirir um exemplar de Roberto Carlos em detalhes por apenas $€ 4,90$. A venda foi proibida apenas no Brasil e o livro, que havia se tornado um artigo caro em sebos nacionais, estava em bancas ao lado de outras pechinchas em Portugal.

\section{Legislação}

Quando um biógrafo está coletando dados sobre alguém, há dificuldade de acesso a informações existentes em bancos de dados governamentais. Essa proteção ocorre em nosso país especificamente porque no passado, esses mesmos dados foram usados contra pessoas que foram perseguidas por terem posicionamento contrário ao regime militar que imperou por décadas no país. O mesmo regime coibiu a liberdade de expressão, levando o legislador a assegurá-la na Constituição Federal que afirma no inciso IX do art. 5ㅇ, consta que "é livre a expressão da atividade intelectual, artística, científica e de comunicação, independentemente de censura ou licença". Então, apesar de certa dificuldade para a obtenção de dados, o direito de expressão livre estava garantida. Com o advento do novo Código Civil, em 2002, através dos artigos 20 e 21 abaixo transcritos, praticamente haveria o impedimento legal da publicação de biografias não autorizadas:

art. 20: Salvo se autorizadas, ou se necessárias à administração da justiça ou à manutenção da ordem pública, a divulgação de escritos, a transmissão 
da palavra, ou a publicação, a exposição ou a utilização da imagem de uma pessoa poderão ser proibidas, a seu requerimento e sem prejuízo da indenização que couber, se the atingirem a honra, a boa fama ou a respeitabilidade, ou se se destinarem a fins comerciais. Parágrafo único. Em se tratando de morto ou de ausente, são partes legítimas para requerer essa proteção o cônjuge, os ascendentes ou os descendentes.

art. 21. A vida privada da pessoa natural é inviolável, e o juiz, a requerimento do interessado, adotará as providências necessárias para impedir ou fazer cessar ato contrário a esta norma.

(grifo meu)

Os artigos do Código Civil entravam em choque com a Constituição Federal devido também ao texto do $\S 20$ do art. 220 que veda "toda e qualquer censura de natureza política, ideológica e artística". O mesmo art. 220 prevê, ainda, no seu caput, que a "manifestação do pensamento, a criação, a expressão e a informação, sob qualquer forma, processo ou veículo não sofrerão qualquer restrição".

A CF é a Lei Magna, isto é, mesmo um texto posterior a ela precisa obedecer seus preceitos. Para dirimir as contradições legais referentes a biografias não-autorizadas, a ANEL (Associação Nacional de Editores de Livros), com a qual estava alinhado Paulo César de Araújo, entrou com uma Ação Direta de Inconstitucionalidade. Todos os nove ministros votaram a favor. Para a relatora, Carmen Lúcia, um voto contrário seria admitir a censura prévia, o que seria inconstitucional. Porém, ressaltou que deve haver reparação caso os biografados sejam vítimas de abuso.

\section{O Réu e o Rei}

Paulo César de Araújo não ficou apenas nas batalhas jurídicas. Após a proibição de seu livro Roberto Carlos em detalhes, escreveu e publicou $O$ Réu e o Rei, onde relata a publicação de sua primeira obra sobre Roberto Carlos, fruto de anos de dedicação e pesquisas que começaram na infância e atravessaram sua vida acadêmica, a incessante busca por fontes, as dificuldades enfrentadas por realizar suas pesquisas apenas com seus próprios recursos financeiros e as batalhas judiciais que provieram do fato do biografado acreditar que sua história era exclusivamente dele e que ninguém poderia contá-la. Nesse relato autobiográfico do biógrafo, Paulo César de Araújo contou novamente muitos episódios que já haviam sido narrados em sua obra proibida sobre seus anos de pesquisa, sobre as numerosas entrevistas, sobre fatos que veio a conhecer sobre seu objeto de estudo e de como involuntariamente virou personagem da história que anteriormente apenas estudava e contava. De outra maneira, em outro contexto, sua história foi recontada e formou o retrato do caso que se tornou o símbolo da luta pela liberdade de expressão e que, diferentemente de outros casos, não é simplesmente o conteúdo publicado que foi posto em questão, mas o próprio direito de se contar uma história que não é individual, mas envolve muitas outras pessoas e interessa a muitas outras mais. Através da biografia de uma pessoa, podemos ter contato com um universo que envolve muitas outras pessoas e muitas outras histórias que combinadas podem formar a História.

\section{CONCLUSÃO}

A história de Paulo César de Araújo, que se dedicou durante anos a estudar a vida do cantor, entrou para a biografia de Roberto Carlos e para a história da defesa da liberdade de expressão no Brasil.

As reviravoltas que viveu por escrever uma biografia aclamada pela crítica e com altas vendagens e que desagradou ao biografado deu origem a uma série de debates. Artistas que anteriormente sofreram e lutaram pela liberdade de expressão, quando o país vivia sob o olhar 
pesado e muitas vezes cruel da censura, posicionaram-se contra a publicação de biografias sem a autorização do biografado, fato que pareceu contraditório por essa obrigatoriedade de autorização para uma biografia ser considerada um tipo de censura.

Por tratar de matéria constitucional, o debate foi parar no Supremo Tribunal Federal, que, em votação unânime, confirmou que exigir a autorização prévia de um biografado ou de sua família para a publicação de uma biografia é uma afronta à liberdade de expressão, liberdade essa que ficou suprimida por muitos anos e que é defendida, ainda que fira os interesses daqueles cujas vidas são retratadas. Entretanto, se houver abusos, autores e editoras podem ter de responder por suas palavras.

O jornalista e biógrafo Alberto Dines afirma que "a fidelidade aos fatos não é inimiga da criatividade" (apud Benchimol, 1995: 101). A garantia da liberdade de publicação de biografias não autorizadas não significa que biógrafos possam escrever o que quiserem. A biografia, autorizada ou não, tem de manter o compromisso com a verdade, posto que não se trata exclusivamente de literatura que, como arte, conta com liberdade criativa. A biografia usa os recursos literários para contar uma história, mas é também gênero do jornalismo e, como tal, requere que os biógrafos sejam responsáveis por suas narrativas e pelos dados que relatam.

O livro Roberto Carlos em detalhes, publicado pela Editora Planeta passou de homenagem a objeto de repulsa do biografado e motivo de mobilizações favoráveis e contra a publicação de biografias não autorizadas. Paulo César de Araújo passou de fã a biógrafo, de biógrafo a réu, de réu a militante e símbolo da luta pela liberdade de expressão. Seu outro livro sobre Roberto Carlos, O Réu e o Rei, publicado pela Companhia das Letras, é a narrativa dessa luta.

\section{REFERÊNCIAS}

BENCHIMOL, Jaime (org.). "Narrativa documental e literária nas biografias", Manguinhos: história, ciências, saúde. Rio de Janeiro, vol. 2, n. 2, jul.-out. 1995, p. 93-113.

BRASIL. Código Civil (2002). Lei n. 10.406, de 10 de janeiro de 2002. Disponível em: http://www.planalto.gov.br/ccivil 03/leis/2002/L10406.htm. Acesso em: 08/08/2016.

BRASIL. Constituição (1988). Constituição da República Federativa do Brasil. Disponível em: http://www.planalto.gov.br/ccivil 03/Constituicao/Constituicao.htm. Acesso em: 08/08/2016.

LE GOFF, Jacques. "Comment écrire une biographie historique aujourd'hui?", le Débat, n. 54, marsavril 1989.

http://entretenimento.uol.com.br/noticias/redacao/2013/10/10/ainda-estou-pagando-pelaproibicao-diz-biografo-de-roberto-carlos.htm. Acesso em 06/08/2016

http://oglobo.globo.com/cultura/livros/proibida-no-brasil-biografia-de-roberto-carlos-vendidaem-saldao-em-lisboa-19393044\#ixzz4Ger04l8b. Acesso em 06/08/2016 